\title{
Textos Pedagógicos Sobre o Ensino da Educação Física
}

Amauri Aparecido Bássoli de Oliveira*

Resumo: O livro Textos Pedagógicos Sobre o Ensino da Educação Física, de Hildebrandt-Stramann, é fruto do trabalho e dedicação da Profa. Dra. Ingrid Marianne Baecker que reuniu vários dos textos produzidos pelo autor no período de 1984 a 1994. A participação de HildebrandtStramann no Programa de Intercâmbio Brasil Alemanha, desenvolvido pela Universidade Federal de Santa Maria no Programa de Pós-Graduação de Educação Física, foi de grande importância e serviu como porta de entrada de seus pensamentos e reflexões sobre a Educação Física, a escola, o movimento e o esporte. Os textos reunidos nesta obra retratam bem os posicionamentos do autor e nos colocam de forma clara e simples a riqueza existente no mundo do movimento humano e como ele pode ser trabalhado dentro do setor educacional, que vai para muito além da função técnicoinstrumental. $\mathrm{O}$ autor trabalha a Educação Física na perspectiva da Fenomenologia e aponta a experiência como ponto crucial a ser considerado no desenvolvimento das ações da área no setor educacional. Trata-se de uma obra significativa e que registra de forma inconteste a participação do autor nas superações pedagógicas tradicionais da Educação Física brasileira.

Palavras-chave: Educação Física, textos pedagógicos, educação e movimento.

Ao iniciar esta resenha quero deixar claro que ela procurará abordar a obra em questão não se atendo exclusivamente a ela, mas procurando fazer um resgate da importância e do convívio proporcionado pela vinda do Prof. Dr. Reiner HildebrandtStramann da Alemanha para o nosso país a partir do ano de 1984. Esta ousadia se faz necessária na medida em que não temos registrado como é que se deu essa convivência e os reflexos, tanto quanto possíveis, originários desta relação para a nossa Educação Física.

O Professor Doutor Reiner Hildebrandt-Stramann é professor titular da Universidade Técnica de Braunschweig, República

* Doutor em Educação Física e professor da Universidade Estadual de Maringá.

Movimento, Porto Alegre, v. 11, n. 1, p.171-182, janeiro/abril de 2005 
Federal da Alemanha. Atuou como professor visitante na Universidade Federal de Santa Maria, no período de 1984 a 1986, e na Universidade Federal de Pernambuco, em 1989. Também foi professor visitante de outras IES federais e estaduais de Maringá, Maceió, Campinas, Florianópolis e Vitória. O foco dos estudos de Hildebrandt-Stramann se dá em pesquisas didáticas sobre aulas abertas à experiência, pesquisas na aprendizagem motora sobre teorias pedagógicas do movimentar-se, pesquisas sobre o desenvolvimento pedagógico na escola (escola em movimento) e pesquisas sobre o mundo do movimento de crianças e jovens.

Atualmente, o autor centra suas pesquisas e esforços no trabalho intitulado "Escola Móvel". Trata-se de uma proposta revolucionária para o processo educacional, pois faz uma mudança geral na configuração dos espaços, do mobiliário, das relações pessoais e das conseqüências dessas alterações no processo ensinoaprendizagem. Ao partir da teoria de que a configuração do ambiente determina as possibilidades das relações humanas, HildebrandtStramann propôs uma revisão geral nesta situação, ou seja, a constituição de um mobiliário totalmente diferenciado e sem regras predeterminadas, assim como uma alteração na configuração dos ambientes para o processo ensino-aprendizagem. Isso provocou o caos na estrutura rígida existente, causando o rompimento com padrões até então sólidos da estrutura didática, o que fez com que houvesse uma mudança geral por parte de todos os envolvidos no processo educacional. Muitas escolas na Alemanha estão aderindo à proposta e provocando sérias mudanças em suas estruturas gerais. Podemos entender que tal experiência ainda está muito longe de nossas escolas, pois nossa estrutura é muito diferente e está muito distante das condições gerais proporcionadas pelo sistema alemão, sejam elas estruturais nos aspectos físicos, materiais e financeiros ou de recursos humanos em relação à capacitação e condições de formação continuada. Não se trata de incapacidade e/ou possibilidade humana, mas de uma estrutura maior e reconhecimento social de que a educação, assim como comentava Freire (1980), ${ }^{1}$ pode ser a mola propulsora das transformações sociais e que só não o é em nosso país, justamente porque poderia sê-lo.

Sem dúvida que poderíamos ter mais desenvolvimento em nosso processo educacional caso ele realmente fosse reconhecido

1 FREIRE, Paulo. Educação como Prática da Liberdade. $11^{a}$ Ed. Rio de Janeiro: Ed. Paz e Terra, 1980

Movimento, Porto Alegre, v. 11, n. 1, p.171-182, janeiro/abril de 2005 
como a riqueza imprescindível do povo. Mas isso é um problema que temos que superar culturalmente, pois isso será conseguido na medida em que esse processo for deflagrado e que nossa população possa ter acesso pleno ao ensino de qualidade e de forma irrestrita.

A busca por Freire para demonstrar o quanto a educação é importante nesta resenha não foi de maneira aleatória dentre tantos outros autores que defendem a educação. Sem dúvida há uma aproximação pessoal em relação aos escritos de Freire, mas a intenção foi a de apresentá-lo relacionando-o à obra de HildebrandtStramann, que o teve como uma das bases para a constituição de sua proposta de Ensino Aberto, além de autores como Brodtmann, Messner e outros. No ano de 1986 foi publicado em nosso país o livro Concepções Abertas no Ensino da Educação Física, de Hildebrandt ${ }^{2}$ e Laging, pela Editora Ao Livro Técnico. Este livro teve sua primeira publicação na Alemanha em $1981^{3}$ e tinha como foco central o trabalho do Ensino Aberto para o nível escolar. No ano de 1982 Landau, outro pesquisador alemão e companheiro de estudos de Hildebrandt-Stramann, trabalhou com a perspectiva de Ensino Aberto para o ensino superior junto ao seu grupo de estudos - "Grupo de Trabalho de Frankfurt". ${ }^{4}$ Neste sentido, fica aqui apresentada a origem do termo Ensino Aberto que teve, nos trabalhos de Hildebrandt-Stramann e Laging, a sua idealização e fundamentação geral.

A década de oitenta foi extremamente importante para a área da Educação Física em nosso país. Houve uma série de alterações em relação a nossa área, foi o momento do refletir e de alterar os rumos de uma prática descompromissada para um novo reordenamento constitucional da área e de sua forma de produção do conhecimento, e quero destacar aqui a influência dos professores alemães Jürgen Dickert e Reiner Hildebrandt-Stramann, que participaram junto ao programa de pós-graduação de Educação Física, da Universidade Federal de Santa Maria - RS. Temos a destacar que esta IES ocupava, neste período histórico, enorme influência em nível nacional sobre os rumos da Educação Física. Esses professores, em suas estadas em nosso país, por intermédio do convênio

2 Reiner Hildebrandt passa a assinar como Reiner Hildebrandt-Stramann a partir do ano de 1990. Para esta resenha estaremos utilizando a nova forma de assinar do autor - Hildebranst-Stramann - independentemente do período referenciado.

3 HILDEBRANDT, R. e LAGING, R. Offene Konzepte im Sportunterricht. Bad Homburg: Limpert 1981.

4 FRANKFURTER ARBEITSGRUPPE (LANDAU, G. et al.): Offener Sportunterricht analysieren und planen. Reinbek: Rororo, 1982.

Movimento, Porto Alegre, v. 11, n. 1, p.171-182, janeiro/abril de 2005 
Brasil e Alemanha (DAAD - Capes), puderam trabalhar com vários profissionais brasileiros que acabaram por ter uma influência significativa dentro do cenário nacional e, como destaque, podemos citar professores como Celi Z. Taffarel, Elenor Kunz, Valter Bracht, Ingrid Marianne Baecker, Maria Augusta S. Gonçalves, Carlos L. Cardoso, Wenceslau Leães Filho, Giovani Pires de Lorenzi, dentre outros.

O Professor Jürgen Dickert foi o primeiro a trabalhar no convênio, sendo seguido pelo Professor Hildebrandt-Stramann que deu continuidade aos trabalhos no programa de pós-graduação da UFSM. Foi nesse momento que tivemos a primeira aproximação com os trabalhos desse professor que falava muito mal o português e que tinha muitas dificuldades para a exposição de suas idéias, obviamente. Mas, bastou meio ano para que pudéssemos perceber a importância de suas idéias, mesmo com as dificuldades iniciais de comunicação que foram se dissipando com a convivência. As maravilhosas rodadas de debates e discussões ao redor de uma churrasqueira e regadas com o delicioso vinho da colônia na velha Santa Maria da Boca do Monte, como costumeiramente é denominada essa acolhedora cidade.

O Professor Hildebrandt-Stramnn chegou com uma série de novas interpretações e considerações sobre o papel da Educação Física e seus profissionais. Foi um momento de profundas reflexões, que iam do papel profissional ao pessoal. Houve nesse momento um repensar geral de nossa parte sobre como entendíamos e praticávamos a Educação Física. Nem todos os integrantes do grupo da pós-graduação (mestrado) se prontificaram a permanecer e a dar continuidade aos debates e reflexões sobre as novas perspectivas. Aqui nós podemos utilizar as denominações de Thomas Khun - havia nesse momento a paralisia de paradigma, ou seja, uma certa resistência, natural e até mesma necessária, às novas possibilidades de intervenção por intermédio da Educação Física.

Para o momento, dentro de nossas inquietações em relação a Educação Física Escolar estavam questionamentos como: como é que não vamos colocar nossos alunos em fila, em ordem para participar das aulas? Como é que nós vamos ficar "refletindo" com os alunos em uma aula de Educação Física? Como não exigir rendimento esportivo e/ou atlético dos nossos alunos durante as aulas? Por que fazer o aluno ficar sentado em uma aula de Educação Física para pensar sobre o seu mundo do movimento? O que é esse mundo do movimento? O que é que Paulo Freire tem a ver com a Educação Física? O que é participar de um projeto de transforma-

Movimento, Porto Alegre, v. 11, n. 1, p.171-182, janeiro/abril de 2005 
ção social? O que é que a Educação Física tem a ver com as questões sociais maiores, para além do esporte?

Todas essas questões, hoje consideradas inocentes, serviram de foco para todos nós que tivemos o privilégio de viver o momento. Um grupo de profissionais formado nas antigas Licenciaturas de três anos, com ênfase técnica e de limitada leitura social. Foi um momento decisivo e altamente significativo para todos nós. Cito para todos, pois foi a partir daí que surgiram obras e trabalhos que até hoje ainda têm reflexo em nossa Educação Física em nível nacional. Todos os profissionais citados anteriormente e que tiveram relação direta com Jürgen Dickert e Hildebrandt-Stramann têm obras de referência no nosso país. Isso é altamente significativo!

Estas questões que para nós eram centrais no momento, fizeram com que Hildebrandt-Stramann se propusesse a produzir um material que pudesse colocar-nos em conflito com velhos paradigmas e que, através dos debates citados, pudéssemos superá-los e avançar em novas concepções. Neste sentido, houve uma série de escritos do autor que foram publicados em vários periódicos no nosso país, tais como a Revista Kinesis da UFSM, Revista do Colégio Brasileiro de Ciências do Esporte - RBCE, Revista da Educação Física/UEM. As contribuições do autor continuaram mesmo após o seu retorno para a Alemanha no ano de 1987, pois sempre que pode ele volta ao nosso país para contribuir com os estudos e participar de eventos técnico-científicos.

Como resultado imediato dos trabalhos de HildebrandtStramann e sob sua coordenação, houve a publicação do livro Visão Didática da Educação Física, com a participação de professores da Universidade Federal de Pernambuco e Universidade Federal de Santa Maria (integrantes do grupo de mestrado e que pertenciam a outras IES do país), publicado pela Editora Ao Livro Técnico no ano de 1991. Destaca-se que nesse período ainda sofríamos com os problemas editoriais, pois um livro para ser editado levava mais de um ano retido nas editoras. Este livro, em especial, apesar de ter ficado pronto no ano de 1988, acabou sendo publicado somente no ano de 1991.

E, agora, fruto de um trabalho maravilhoso da Profa. Dra. Ingrid Marianne Baecker, foram reunidos alguns trabalhos centrais de

5 Como mais uma indicação, acabou de ser editado o livro Intercâmbios Científicos Internacionais em Educação Física e Esportes, sob a organização de HildebrandtStramann e Kunz, pela Editora Unijui - RS, 2004, em que vários desses profissionais citados têm participação.

Movimento, Porto Alegre, v. 11, n. 1, p.171-182, janeiro/abril de 2005 
Hildebrandt-Stramann neste livro intitulado Textos Pedagógicos Sobre o Ensino da Educação Física, editado pela Editora Unijuí - RS. Assim como nós, a Profa. Baecker teve uma convivência intensa com o autor, tanto no Brasil como na Alemanha quando de seu doutorado.

Como relatado na trajetória da estada de Hildebrandt-Stramann em nosso país, assim como nos trabalhos que realiza, nada mais apropriado do que o título escolhido para o livro, pois retrata bem as preocupações do autor e de seus trabalhos. Trata-se de uma preocupação centrada no ensino da Educação Física em nível escolar e na formação de profissionais para seu atendimento.

A obra traz a reprodução de sete artigos que HildebrandtStramann produziu e publicou em nossos periódicos nacionais. Eles foram organizados em três grandes temáticas: Reflexões críticas sobre o conceito de esporte; Reflexões pedagógicas sobre teorias de movimento e Reflexões sobre educação nas aulas de Educação Física.

Na primeira temática há uma preocupação central em contextualizar o esporte e como este pode e deve ser trabalhado dentro do setor educacional sem reduzir a sua complexidade. A maior crítica apresentada pelo autor é a redução do grau de complexidade atribuído ao esporte quando este é trabalhado no setor educacional. Com a redução do grau de complexidade, o esporte é visto apenas como uma série de ações motoras e regras gerais que devem ser obedecidas, sem a devida discussão e as inúmeras possibilidades motoras que podem ser exploradas. Neste sentido, o autor nos apresenta três tendências que são apoiadas através do sistema esportivo: a tendência para a seleção, a tendência para a especialização e a tendência para a instrumentalização. Isso empobrece e reduz a potencialidade desse fenômeno social que é o esporte. A superação dessa forma de entender e praticar o esporte em nível escolar é o foco central das idéias defendidas por Hildebrandt-Straman, em que a sua superação e o aproveitamento das riquezas em suas múltiplas dimensões motoras, históricas, fisiológicas, biomecânicas, lúdicas, competitivas, sociais, educacionais e outras são possibilitadas por esse fenômeno.

Neste sentido, o autor defende a necessidade de que, no setor educacional, o esporte possa ser modificado de forma a transcender sua matriz original e que acabe por atender aos interesses e necessidades dos participantes da ação. As regras constitutivas e regulativas $^{6}$ do esporte devem ser alteradas de acordo com os gru-

6 Para maiores esclarecimentos sobre as regras constitutivas e regulativas verificar o livro Visão Didática da Educação Física. Grupo de Trabalho Pedagógico. Rio de Janeiro: Editora Ao Livro Técnico, 1991.

Movimento, Porto Alegre, v. 11, n. 1, p.171-182, janeiro/abril de 2005 
pos que interagem na ação. O esporte deve ser entendido como meio e não o fim único da Educação Física Escolar.

Dando continuidade às discussões sobre o fenômeno esportivo, Hildebrandt-Stramann nos mostra a necessidade do rompimento com o entendimento de que as aulas de Educação Física deveriam seguir as mesmas rotinas das sessões de treinamento, ou seja, a rotina do modelo parcial para o global. De acordo com o autor, para as aulas deveríamos proporcionar uma possibilidade pedagógica de caminho inverso, ou seja, do global para o parcial. As crianças deveriam se defrontar com o esporte em sua grande complexidade e entendê-lo dentro dessa complexidade. O modelo tradicional foi fortemente trabalhado pelas teorias da aprendizagem motora nos anos 70 e 80 e tiveram influência direta nas aulas de Educação Física dentro da escola. Essa nova perspectiva também pode ser visualizada em obras de autores como Piaget (Teoria Construtivista), Paulo Freire (Educação Libertadora), Gordjin e Tamboer (Compreensão Dialógica), Saviani (Tendência Histórico-Crítica), Hildebrandt-Stramann e Laging (Ensino Aberto), todos autores que superaram uma visão reducionista do ensino e da forma como o homem aprende.

Assim, em relação à questão do esporte nas aulas de Educação Física, o autor defende claramente a superação das duas regras básicas impostas por este fenômeno: a regra do sobrepujar e a regra da comparação objetiva. Segundo o autor, estas duas regras reduzem o grau de complexidade do fenômeno esportivo. Esse fenômeno social - o esporte - podemos citar como sendo um dos maiores na atualidade, é defendido de forma acertada pelo autor como um conteúdo imprescindível e rico para ser contemplado no processo educacional da Educação Física, contudo, deve ser redimensionado e explorado ao máximo para que suas riquezas culturais e motoras não sejam reduzidas. Esse foi um período dentro da área que por vezes se chegou a negar o esporte, entretanto, destaca-se que essa negação sempre foi pautada nesse entendimento reducionista atribuído ao esporte dentro do setor educacional. As contribuições de Hildebrandt-Stramann para essa superação e entendimento das riquezas do fenômeno foram significativas para todos que atuam com a Educação Física Escolar.

Para a segunda temática, a Profa. Baecker selecionou dois artigos que retratam a questão da experiência como requisito didático imprescindível e fundante da ação do professor nas aulas e também a visão pedagógica do movimento. Nestes artigos o autor procurou demonstrar, por intermédio de exemplos práticos, como aulas e experiências do cotidiano, de como se faz necessário que os professo-

Movimento, Porto Alegre, v. 11, n. 1, p.171-182, janeiro/abril de 2005 
res acatem e respeitem as experiências dos alunos dentro do processo educacional. Já no século XVIII, definido como o século pedagógico, entendia-se que a criança não era uma tábula rasa. Porém, as ações e encaminhamentos didático-pedagógicos adotados em grande parcela das escolas na atualidade parecem ainda não respeitar tal entendimento. Em um novo artigo, publicado neste periódico, Hildebrandt-Stramann resgata o livro de Paulo Freire Cuidado Escola, justamente para introduzir a sua crítica ao fato de as crianças serem colocadas de forma imóvel e como se fossem apenas receptáculos dos conhecimentos a serem passados pelos professores.

Para o autor a experiência do mundo da vida é a experiência dos sentidos e, com isso, defende que a experiência do mundo da vida é ligada ao corpo. Os sentidos estão no corpo, por isso, a experiência do mundo da vida é um tipo de experiência cinestésica. Com isso, o autor tece duras críticas à forma como são trabalhadas as aulas de Educação Física, em que se nega a experiência dos participantes e se direciona as ações didáticas no sentido de encurtar caminhos para o aprendizado das formas institucionalizadas do esporte performance e de padrões motores determinados.

Neste sentido, Hildebrandt-Stramann nos lança como desafio visualizar o homem que salta e não o salto em si. Até então, podemos dizer que observávamos o salto e nos esquecíamos do sujeito que saltava. Este fato resgata toda a exposição que temos feito até o momento, ou seja, há aqui a ruptura de paradigmas. A superação do paradigma técnico-instrumental (científico-natural) para o paradigma fenomenológico. É aqui que o autor nos demonstra, de forma direta e com exemplos de aulas, como é que podemos e devemos respeitar a experiência do mundo da vida dos participantes e como os sentidos pedagógicos podem ser contemplados no processo ensino-aprendizagem, respeitando-se as limitações, interesses e necessidades dos participantes do processo. Para tanto, o autor aponta alguns princípios pedagógicos de ensino que indicam: a necessidade de possibilitar a busca autônoma dos participantes pelos seus padrões de movimentos, em que a exploração do problema resulta da experiência e, nessa busca, o professor deve assessorá-los com conhecimento suficiente para auxiliá-los; que seja valorizado o princípio da totalidade desde o início; que se faça uso de metáforas na informação verbal e que se crie e recrie ambientes propícios à exploração da maior variedade possível de ações motoras.

7 HILDEBRANDT-STRAMANN. Escola (s)em movimento. Movimento. Revista da Escola de Educação Física da Universidade Federal do Rio Grande do Sul. Porto Alegre, v.11, n.1, jan./abr. 2005.

Movimento, Porto Alegre, v. 11, n. 1, p.171-182, janeiro/abril de 2005 
Dentro desta segunda temática o autor possibilita-nos uma visão plena da teoria do Ensino Aberto, em que há profundo respeito aos alunos e ao seu repertório de experiências, assim como lança como desafio a utilização do mundo do movimento para além das formas estereotipadas. Com isso, nos faz recordar os trabalhos de Freire em suas ações iniciais que partiam do mundo dos sujeitos a serem alfabetizados para então levá-los à aquisição de conhecimentos mais complexos e que pudessem responder às inquietações de seus cotidianos, buscando suas conscientizações para além do entendimento da junção de letras, mas sim para o que elas representavam gráfica e socialmente. Da mesma forma, Hildebrandt-Stramann nos leva a entender a necessidade de considerar o mundo do movimento dos envolvidos em nossas aulas para que através deles possamos ampliar os entendimentos e transcender ao puro fazer, porém sem perder o prazer em realizá-los e recriá-los, possamos constituir em nossos alunos a consciência do seu fazer motor e social.

Como terceira temática foram selecionados dois artigos que dão o tom à obra de Hildebrandt-Stramann em nosso país. Uma apresentação sintética de como deve ser trabalhada a Educação Física dentro da perspectiva do Ensino Aberto e de como as questões metodológicas devem ser desencadeadas.

O entendimento de educação apresentado pelo autor deixa claro que em sua proposta busca-se a todo o momento a independência dos participantes em todos os sentidos. Para tanto, o autor defende que dentro das ações didáticas se procure atuar em condições de co-responsabilidade, na qual os alunos, juntamente com o professor, busquem soluções em conjunto para os problemas, da mesma forma que ampliem a complexidade dos problemas propostos. Neste sentido, há uma defesa constante para que se trabalhe no processo ensino-aprendizagem e se possibilite aos alunos a capacidade de ação. Com isso, quer se demonstrar que os alunos, ao término de suas participações, possam ser autônomos frente aos conhecimentos e ações tratados em aula, com possibilidades de transcendê-los.

Contudo, Hildebrandt-Stramann coloca que para que haja esse entendimento e essa prática, faz-se necessária uma mudança metodológica no ensino da Educação Física. Os professores de Educação Física carecem de uma reformulação geral em suas ações didáticopedagógicas, para além da reprodução sistematizada de conhecimentos e com respeito ao processo histórico dos participantes, suas experiências e possibilidades de autonomia. Não há espaço, dentro desta proposta defendida pelo autor, para ações refratárias e que

Movimento, Porto Alegre, v. 11, n. 1, p.171-182, janeiro/abril de 2005 
não perspectivam a autonomia dos participantes. Assim, entendese que para que haja a promoção da citada autonomia aos participantes há que existir, por parte dos professores, a devida conscientização de suas potencialidades acadêmicas profissionais.

Assim, a obra de Hildebrand-Stramann coloca-se como um ponto de referência e marco histórico para a área da Educação Física. Os entendimentos e ensinamentos apresentados pelo autor sobre o homem, a sociedade, a educação e o esporte superam uma simples leitura contextual, eles nos demonstram como a Educação Física é imprescindível ao processo formativo de nossa sociedade, que esperamos, seja cada vez mais emancipada e autônoma.

Certamente, esta obra deve ser referência para os cursos de formação de professores de Educação Física e também para os profissionais de forma geral que trabalham com a educação e o esporte. A visão do autor sobre os temas abordados, a qual foi descrita de forma simples e totalmente acessível, só poderá contribuir com a ampliação do entendimento geral sobre a nossa área e sua importância social.

Por fim, temos que agradecer à Profa. Dra. Ingrid Mariane Baecker pelo belo trabalho realizado na junção de textos tão significativos para a nossa área e que, com certeza, terão registro histórico em nossa trajetória.

Movimento, Porto Alegre, v. 11, n. 1, p.171-182, janeiro/abril de 2005 
Pedagogical articles on the instruction of Physical Education, by Reiner Hildebrandt-Stramann, ljuí: UNIJUÍ, 2003 (Physical Education Collection)

Abstract: "Pedagogical articles on the instruction of Physical Education" is a book by Reiner HildebrandtStramann which is the result of Prof. Dr. Ingrid Marianne Baecker's work on the compilation of several articles produced by Hildebrandt-Stramann from 1984 to 1994. His participation on the Brazil-Germany Exchange Program, developed by the Universidade Federal de Santa Maria for the program of post-graduation on Physical Education, was extremely important and it launched several of his thoughts about Physical Education, schools, sport and movement. The articles compiled in the book convey those thoughts and show, in a clear and simple way, how rich the world of human movement is and how it can be taught in creative ways rather than the traditional technical/ instrumental approach. The author deals with Physical Education under the perspective of Phenomenology and argues that one's experience is a crucial aspect for the development of activities in the educational area. It is an outstanding book that shows how Hildebrandt-Stramann contributed to the development and improvement of the Brazilian traditional Physical Education.

Keywords: Physical Education, pedagogical articles, education, movement. 
Textos pedagógicos sobre la enseñanza de la Educación Física, por Reiner Hildebrandt-Stramann, Ijuí: UNIJUí, 2003 (Coleción Educación Física)

Resumen: El libro Textos Pedagógicos Sobre la Enseñanza de la Educación Física, de Hildebrandt-Stramann, es fruto del trabajo y dedicación de la Profa. Dra. Ingrid Marianne Baecker que reunió varios de los textos producidos por el autor en el período de 1984 a 1994. La participación de Hildebrandt-Stramann en el Programa de Intercambio Brasil Alemania, desarrollado por la Universidade Federal de Santa Maria en el Programa de Pós-Grado de Educación Física, fue de gran importancia y sirvió como puerta de entrada de sus pensamientos y reflecciones sobre la Educación Física, la escuela, el movi-miento y el deporte. Los textos reunidos en esta obra retratan bien los posicionamientos del autor y nos colocan de forma clara y simple la riqueza existente en el mundo del movimiento humano y como él puede ser trabajado dentro del sector educacional, que va mucho allá de la función técnico-instrumental. El autor trabaja la Educación Física en la perspectiva de la Fenomenología y apunta la experiencia como punto crucial a ser considerado en el desarrollo de las acciones del área en el sector educacional. Trátase de una obra significativa y que registra de forma inconteste la participación del autor en las superaciones pedagógicas tradicionales de la Educación Física brasileña.

Palabras-clave: Educación Física, Textos Pedagógicos, Educación y Movimiento. 